scientific and technical literature, but there is no certainty that the publications not taken by the British Museum will be found in some other British library, still less that, if acquired, they will be preserved. He suggested that the consultation and co-operation in this field already begun between the British Museum and other government libraries should be extended to the various national and university libraries and put on a systematic basis. Each library, while continuing to acquire the publications likely to be called for by its own readers, would undertake responsibility for acquiring, in particular fields to be allotted to it, the publications which, because of their obscurity or very restricted interest, are at present neglected. The British Museum, apart from developing more thoroughly its collections in the fields where it is already particularly strong, would acquire the books to which no one else is prepared to give house-room and would store those which every other library would prefer to discard. A natural corollary of such a system of co-ordination would be the making of a union catalogue of all the books to which it applies, giving at least one location for each book. In conclusion, Mr. Chaplin indicated the willingness of the Museum authorities, as part of any such projects, to make, after wide consultation, such changes in Museum practices as would bring them into harmony with the majority of co-operating libraries and remove present obstructions. Any such scheme, however, would require greatly increased resources in staff, in money and in buildings, and they will only be forthcoming if these demands are presented to Parliament backed effectively by influential opinion.

The place of the non-public library in the library system was considered by Mr. E. A. Baker, librarian in the Ministry of Food, in a paper also read on September 30. Stressing the need for greater cooperation between all types of libraries, Mr. Baker suggested that each public library participating in one of the subject specialization schemes recently set up in some of the regional bureaux should be able to look to a specialist library in its particular field for assistance in book selection and bibliographical information. He also suggested that the time has come for a thorough investigation into the constitution and organization of the Library Association with special reference to the representation of the non-public libraries.

Mr. W. B. Paton's paper on "Standards of Library Staff : Recruitment and Training", read on September 29, stressed the dependence for success of a library service on the quality of its staff. The general education of librarians should, he maintained, reach the standard at present demanded by the Library Association from examination candidates, and for preference should surpass it. This could be possible if the same rigid standards were not applied to the non-professional categories whose service is likely to be temporary. He also thought the division of staffs into professional and non-professional categories should become the declared policy of the Library Association as soon as possible, that university graduates should be welcomed as recruits to the library service and that in time this would be a normal standard of entrance. He urged that the time has come for the Library Association to reconsider its examination syllabus to relate it more closely to the needs of special libraries. He also suggested that the conduct of the examinations should be integrated with the activities of the schools of librarianship. The number of these schools should be reduced, but the qualifications of their teaching staffs should be raised and opportunity sought to link the schools with universities. A personal interpretation. of the office of librarian, given by Mr. F. Raymond Smith, librarian of the Guildhall, on Soptember 28, also stressed the importance of the professional ideal and discussed the closer adjustment of professional training to the needs of special libraries, and the related issues of the common structure and functions of both special and municipal libraries and librarians. On Oetober 1, Mr. Bengt Hjelmqvist, head of the Library Board in Sweden, described the operation of public libraries in Sweden under fifty years of State aid.

\section{FIFTH INTERNATIONAL SPECTROSCOPY COLLOQUIUM}

7 HE fifth International Spectroscopy Colloquium, organized by Prof. F. X. Mayer, chairman of the Spectrochemistry and Colorimotry Group of the Austrian Society of Chemists, was held at Gmunden, Salzkammergut, Upper Austria, during August 30September 3. More than five hundred members attended, representing twenty-three countries, and the importance to practical spectroscopy of these international gatherings is shown by the significant increase in the number of participants on each successive occasion. Two days were allotted to each of the principal sections-emission spectroscopy and molecular spectroscopy-with a mid-week excursion to the Nitrogen Works and Steel Works at Linz. The meetings were held at the Town Theatre, while a one-day symposium on direct-reading spectroscopy was held concurrently at the Kurhotel.

Emission spectroscopy. Three papers dealt with the analysis of silicates and silicate rocks and similar materials, for which various types of arc excitation are used. Progress in the detection of sulphur and halogens by high-current, low-voltage, short-duration spark discharges was reported, followed by studies of arcs and sparks in different atmospheres, highly reproducible 'sparking-off' phenomena and the stroboscopic examination of controlled sparks. A new atomizer using electrostatic spraying for flame analysis was described, and the use of amyl alcohol has been found to give a three-fold increase in accuracy and sensitivity in detecting calcium and magnesium.

Further studies of the Standard Paper Density Scale were discussed; improved results have been obtained with scale lines having a profile similar to that of spectrum lines. In determining the absolute error of photometric measurements, the use of polarization prisms is least open to objection, provided that the prisms are in perfect condition. Other subjects included errors in the 'method of additions', calibration with the rotating step-sector and devices for producing linear calibration graphs. Advances in equipment concerned microphotometers (one incorporating a recording electro-dynamic oscillograph, and the other an electric comptometer with a printing dovice), stigmatic grating spectrographs, and a plane grating in convergent light for the study of hyperfine structure and isotope shifts.

Direct-reading spectroscopy. A now universal quantometer and two British designs of the polychromator type (a grating instrument and an attach. ment to a quartz instrument) were described. Other 
papers dealt with the analysis of aluminium alloys and steels, the use of the reflected image as an internal standard and a systematic study of iron + nickel +1 per cent chromium and iron + cobalt + 1 per cent chromium alloys.

Molecular spectroscopy. Analytical applications of emission and absorption spectra in the vacuum ultra-violet were reviewed; photo-ionization of oxygen and other gases was reported in this region of the spectrum, and cross-sections have been calculated from intensity measurements. Other contributions dealt with the structure and composition of siliceous materials, the estimation of the insecticide parathion and the identification of components of fats and metal soaps.

A method of correcting ultra-violet spectra of macromolecules (proteins) for Tyndall or Rayleigh scattering was deseribed. Changes of spectra with $p \mathrm{H}$ have been assigned to ionization of phenolic groups of tyrosin in albuminoids. The results given on double bonds in relation to the dependence of Raman line intensities on excitation frequency are not in accord with Placzek's theory. Vibrationrotation bands of $\mathrm{C}_{2}, \mathrm{CN}, \mathrm{CH}$ and $\mathrm{CO}$ in infra-red flame spectra and determinations of flame temperatures were discussed. Microwave data on deuterated derivatives indicate the exact structure of the pyridine molecule, and the effect of solvent and hydrogen bonding on the dipole moment of pyrrole is related to shifts in the NH frequency. Work on hydrogen bonding, particularly water in silica gels, was reviewed. It is concluded from infra-red studies of structure and intermolecular interactions of the amide group that dipole-dipole interaction rather than hydrogen bonding is the controlling factor in polyamide and polypeptide structures. Many overtone and combination bands have been identified in near infra-red spectra of polypeptides and proteins, using polarized radiation. Studies of the spectro of amorphous and crystalline celluloses, using the hydrogen-deuterium exchange, were reported, and the ultra-violet absorption of cellulose xanthogenate has been analysed by analogy with simpler organo-xanthates.

New designs of spectrophotometers and a partly mechanical, partly electronic, 'memory system' for converting a single-beam spectrometer to give percentage absorption traces were described. A punched-card system of documentation was demonstrated, and the 1954 Ohio State meeting was reviewed. In addition, three papers were presented on X-ray fluorescence spectroscopy.

The innovation of holding pre-arranged evening discussions proved successful, and it is hoped to extend this feature on future occasions. The four topies selected were: experiences with methods not requiring standards for comparison, using different techniques; the evaluation of spectrograms (in this discussion the desirability of international standardization of symbols, definitions and analytical methods was stressed and referred for action at the next Colloquium); $a_{0}$ comparison of relative sensitivitios of the eye, the photographic emulsion and electrical radiation receivers, in spectrophotometric work; and the equipment and technique of Raman spectroscopy -its analytical possibilities and scope in comparison with infra-red methods.

A somewhat fuller summary of the proceedings of the Colloquium, giving the authors and brief notes on the papers presented, is being published in a "Spectroscopic Conferences Supplement" to the forthcoming December issue (No. 14) of the British Bulletin of Spectroscopy. A complete record of the papers and discussions will be published in a special volume of Microchimica Acta (Springer-Verlag, Vienna) in 1955. Proposals for the Sixth Colloquium were discussed at a committee meeting attended by delegates from fourteen countries. Possible broadening of the scope to include the physics of spectra, with joint or consecutive meetings with other bodies, was considered. However, it was decided to continue the organization on lines similar to those of previous occasions, but with more emphasis on prearranged discussions on selected topies. It was finally agreed that the next Colloquium should be held in Holland in the autumn of 1956.

D. M. SмITH

\section{APPLIED RESEARCH IN TECHNICAL COLLEGES}

A SPECIAL committee of the London and Home Counties Regional Advisory Council for Higher 'Technological Education has issued a report on applied research in technical colleges*, based on information supplied by seventeen out of the twenty five colleges in the region approached by the committee. The Council is satisfied that the report covers substantially all the published research undertaken in technical colleges in the region during 1947-52, and some 330 original contributions to scientific or technological knowledge are listed in an appendix, the great majority being in physical, inorganic and, especially, organic chemistry. There is also some bias towards biology; but the Council comments that relatively few of the published researches in organic chemistry appoar to have been undertaken in direct co-operation with industry.

An appended list of research projects undertaken at the direct request of industry indicates that technical colleges have helped and are helping in the investigation of engineering problems in circumstances in which no question of publication arises, and a further appendix gives examples of co-operation between technical colleges, research organizations and government departments, including the Department of Scientific and Industrial Research. The Council considers, however, that there is room for a considerable increase in the amount of work done in consultation with industry or for industry's direct benefit, and supports the view that one important function of technical colleges is to train research technologists for industry (especially, perhaps, for the engineering industry) and that fundamental research provides an admirable training in research methods. It suggests that here the technical colleges could be of particular assistance to the small firm, and that the investigations now in progress by parttime students, possibly working for a master's or a doctor's degree, represent a fruitful line of co-operation by which the resources of the colleges may, by agreement, be used by an individual nominated by $a$ firm to conduct a relatively long-term investigation in which the firm is interested. An appendix to the report shows that during the period four doctorates in science, 105 Ph.D.s and 104 M.Sc. degrees of the University of London were awarded for research carried out in the technical colleges of the region.

* Applied Research in Technical Colleges. Pp. 44. (Publication

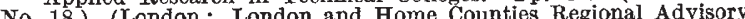
Council for Higher Technological Education, 1954.) 2s. $6 d$. 